\title{
Endoscopic gallbladder stenting using a rendezvous technique for cholecystitis after metal stent placement in a patient with malignant hilar biliary stricture
}

A 75-year-old man was admitted with right hypochondralgia and high fever due to cholecystitis, concomitant with unresectable cholangiocarcinoma. He had undergone endoscopic partial stentin-stent (PSIS) placement of triple selfexpandable metal stents (SEMSs) for jaundice due to a Bismuth type IV malignant hilar biliary stricture 11 months previously [1], and placement of plastic stents within the SEMSs for recurrent biliary obstruction 2 months previously, using a short double-balloon enteroscope (DBE; El-B530, Fujifilm, Tokyo).

Percutaneous transhepatic gallbladder drainage (PTGBD) was performed for treatment of his cholecystitis, and his condition improved immediately ( $>$ Fig. 1 a). However, permanent gallbladder drainage was required because recurrent cholecystitis occurred without ongoing PTGBD. Accordingly, endoscopic gallbladder stenting (EGS) was attempted via the papilla of Vater using a short DBE, but insertion of the guidewire into the gallbladder through the SEMSs was difficult. A 0.025-inch guidewire (Visiglide 2; Olympus, Tokyo, Japan) was however successfully inserted via the percutaneous route from the gallbladder through the SEMSs and into the duodenum. Following advancement of a short DBE to the papilla of Vater, the guidewire was firmly grasped with a snare (Captivator II; Boston Scientific, Natick, Massachusetts, USA) and withdrawn through the DBE.

EGS was accomplished by the guidewire being exchanged with a 0.035-inch guidewire (Revowave; Olympus), which was inserted from the endoscope side to the outside of the body, using a 5.5-Fr catheter (PR-V234Q; Olympus) (\$ Fig. 1 b). Following this, it was possible to advance a 7-Fr pig-tailed stent (Gaderius, Tokyo, Japan) through the SEMSs into the gallbladder while fixing both ends of the guidewire ( $\mathbf{F i g . 1}$ c). The stent was then successfully placed after the tip of the guidewire had been released ( $>$ Fig. $\mathbf{1 d}$;
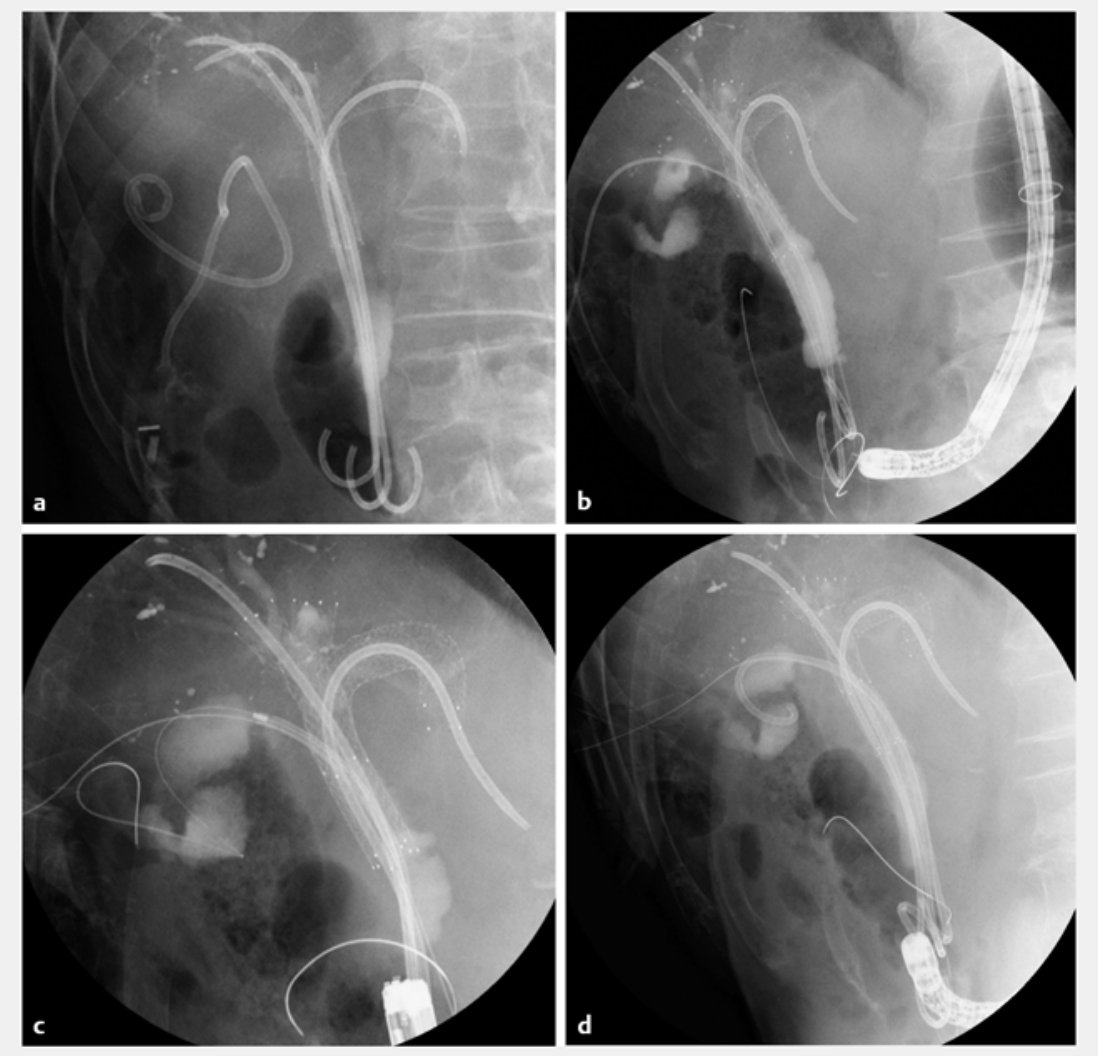

- Fig. 1 Radiographic images showing: a the plastic stents that had been inserted into the intrahepatic bile ducts through the metal stents and the percutaneous transhepatic gallbladder drainage (PTGBD) tube that had been inserted for treatment of cholecystitis; $\mathbf{b}$ the exchanged 0.035 -inch guidewire that was passed from the endoscope side to the outside of the body via a catheter; $c$ a plastic stent being inserted into the gallbladder through the mesh of the metal stent; $\mathbf{d}$ the plastic stent in position after the tip of the guidewire had been released outside of the body.

- Video 1). PTGBD was not required again and the patient experienced no further recurrent cholecystitis before his death 5 months later.

EGS using a rendezvous technique for cholecystitis after SEMS placement was useful in this patient because it facilitated insertion of both the guidewire and the stent across the interstices of the SEMSs.

Endoscopy_UCTN_Code_TTT_1AR_2AJ
Competing interests

None

The Authors

Shigeru Horiguchi, Koichiro Tsutsumi, Hironari Kato, Hiroyuki Okada Department of Gastroenterology and Hepatology, Okayama University Graduate School of Medicine, Dentistry, and Pharmaceutical Sciences, Okayama, Japan 


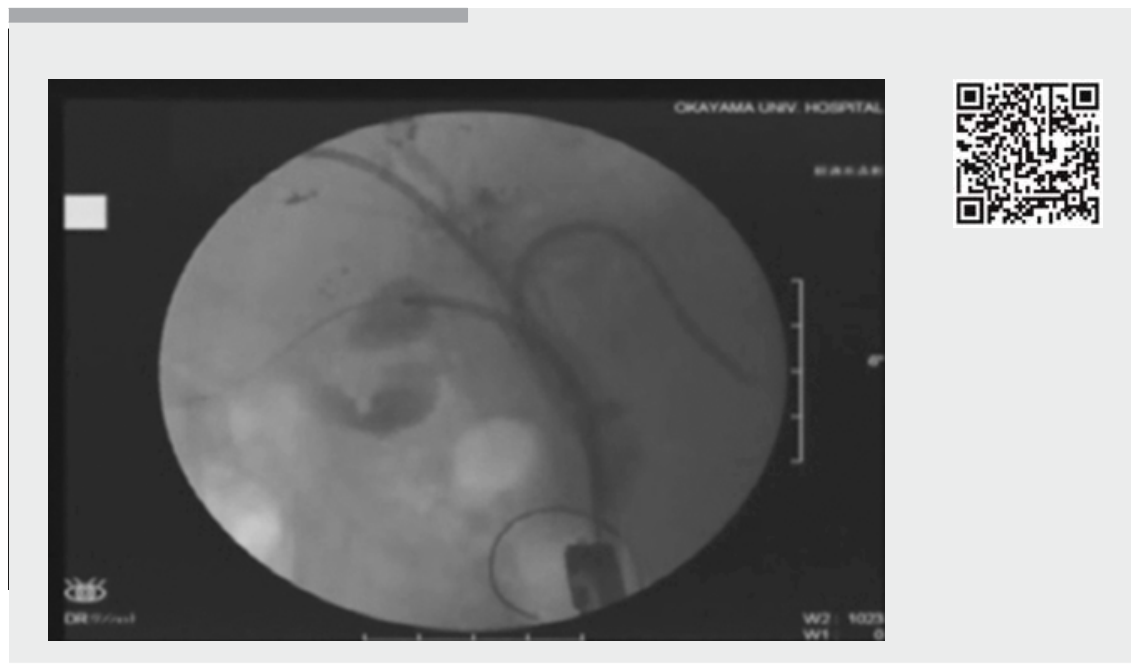

$\checkmark$ Video 1 A guidewire was inserted through the interstices of the metal stents via the percutaneous route. The guidewire was grasped by a snare and then withdrawn through the scope. A catheter was inserted over the guidewire, from the scope to the outside of the body. A second guidewire was then passed from the scope to the outside of the body. With both ends of the guidewire grasped, a plastic stent was endoscopically inserted through the interstices of metal stent and into the gallbladder. The stent was successfully placed in the gallbladder following release of the tip of the guidewire.
Corresponding author

\section{Koichiro Tsutsumi, MD, PhD}

Department of Gastroenterology and Hepatology, Okayama University Graduate School of Medicine, Dentistry, and Pharmaceutical Sciences, 2-5-1 Shikata-cho, Kita-ku, Okayama 700-8558, Japan

Fax: +81-86-2255991

tsutsumi@cc.okayama-u.ac.jp

\section{Reference}

[1] Tsutsumi K, Kato H, Okada $\mathrm{H}$ et al. A novel technique for partial stent-in-stent placement of three metal biliary stents using a short double-balloon enteroscope. Endoscopy 2014; 46 (Suppl. 01): E417-E418

\section{Bibliography}

DOI https://doi.org/10.1055/s-0043-108543

Published online: 5.7.2017

Endoscopy 2017; 49: E204-E205

(c) Georg Thieme Verlag KG

Stuttgart · New York

ISSN 0013-726X

\section{ENDOSCOPY E-VIDEOS}

https://eref.thieme.de/e-videos

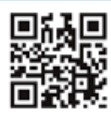

Endoscopy E-Videos is a free access online section, reporting on interesting cases and new

techniques in gastroenterological endoscopy. All papers include a high quality video and all contributions are freely accessible online.

This section has its own submission website at https://mc.manuscriptcentral.com/e-videos 